\title{
MONITORAMENTO AMBIENTAL \\ MAPEAMENTO DO USO E OCUPAÇÃO DO SOLO DA SUB-BACIA DO CÓRREGO DO SAPÉ
}

Tiago José Vieira - tj.vieira01@gmail.com

Centro Universitário Patos de Minas-UNIPAM

Ana Gabriela de Sousa Balator Silva - anagabrielasbs@ hotmail.com

Centro Universitário Patos de Minas-UNIPAM

Willian Geraldo da Silva - williang18@ hotmail.com

Centro Universitário Patos de Minas-UNIPAM

Letícia Santos Pinheiro Alcântara - leticiasantos_ptc@ hotmail.com

Centro Universitário Patos de Minas-UNIPAM

Danielle Betânia Pereira - daniele_betania@ hotmail.com

Centro Universitário Patos de Minas-UNIPAM

Regina Célia Gonçalves - reginacelia@ unipam.edu.br

Centro Universitário Patos de Minas-UNIPAM

Resumo: As atividades agrossilvipastoris, pela sua própria característica, têm se mostrado como relativamente impactante, perdendo somente para as atividades de mineração. Desse modo é de grande importância realizar o monitoramento do uso de ocupação de solo principalmente em áreas de importância para a sociedade. Assim, este trabalho teve como objetivo realizar o mapeamento do uso e ocupação do solo da sub-bacia do Córrego Sapé, localizada no município de Lagoa Formosa/MG. O mapeamento foi dividido em três etapas, sendo elas a delimitação da sub-bacia, o tratamento das imagens e a geração do mapa de uso e ocupação do solo, utilizando em todas as etapas o software de SIG ArcGis, versão 10.2. Os resultados demonstraram que o uso do solo predominante nesta sub-bacia é dado pela classe Pastagem, seguida pelas classes Cultura Anual, Mata Nativa, Solo Exposto e Infraestrutura Urbana, respectivamente. Deste modo, conclui-se que grande parte da sub-bacia encontra-se sob uso antrópico e que a compreensão da dinâmica de ocupação do solo e de sua interferência nos processos naturais é fundamental para o estabelecimento de ações de planejamento socioambiental para a sub-bacia hidrográfica.

Palavras-chaves: Diagnóstico, Levantamento, Solo, Ocupação. 

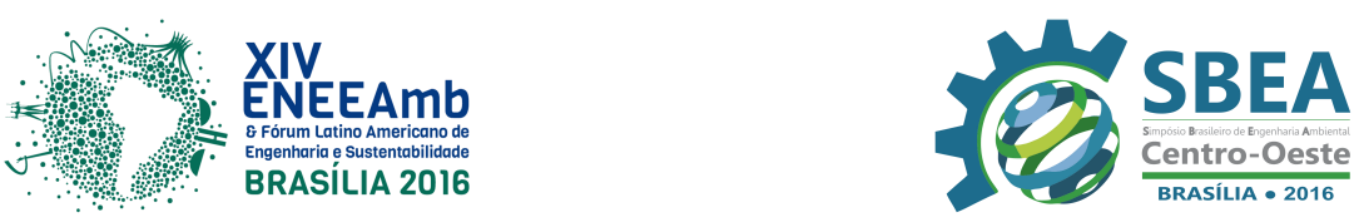

\section{INTRODUÇÃO E OBJETIVOS}

A qualidade e quantidade hídrica de uma sub-bacia hidrográfica podem ser afetadas pelas modificações decorrentes na ação humana, no uso e ocupação do solo, ocasionando graves impactos ambientais (SILVA et al., 2010).

A expressão "uso e ocupação do solo" faz referência à forma como o espaço geográfico é ocupado e seu estudo consiste em buscar informações de sua utilização pelo homem ou não, caracterizar os tipos de categorias de cobertura vegetal nativa que reveste o solo e as suas localizações (ROSA, 2003).

Deste modo, o estudo e mapeamento do uso e ocupação do solo são considerados uma importante ferramenta para o conhecimento das alterações e transformações das características da paisagem, proporcionando, assim o direcionamento de práticas conservacionistas com vista ao desenvolvimento sustentável (SANTOS \& SANTOS, 2010).

A utilização de técnicas e aplicação do SIG (Sistemas de Informações Geográficas) no mapeamento de uso e ocupação de solo tornou-se um instrumento de grande importância, pelo fato de propiciar maior frequência na atualização de dados, precisão nas análises, agilidade no processamento e viabilidade econômica (VAEZA et al., 2010).

Assim, tendo em vista que tal mapeamento é extremamente fundamental para a compreensão da organização do espaço, o presente estudo teve por objetivo realizar o mapeamento do uso e ocupação do solo, utilizando as técnicas do SIG por meio do software ArcGis (10.2), da sub-bacia hidrográfica do córrego do Sapé, localizada no município de Lagoa Formosa/MG. Tal estudo se justifica pela importância que tal sub-bacia possui, uma vez que o córrego do Sapé é o principal corpo hídrico que abastece a cidade de Lagoa Formosa, além de ser um dos principais afluentes da bacia hidrográfica do Rio Paranaíba. Além disso, por estar localizado em uma região de expansão da fronteira urbana, vem sofrendo diversas modificações de ordens socioeconômicas e ambientais, sendo urgente a adoção de medidas de gerenciamento.

\section{METODOLOGIA}

\section{1 Área de estudo}

O estudo foi desenvolvido na sub-bacia hidrográfica do córrego do Sapé, que está localizada na porção leste do município de Lagoa Formosa, mesorregião do Triângulo Mineiro/Alto Paranaíba, oeste do estado de Minas Gerais (Figura 1). Essa sub-bacia pertence aos domínios da bacia hidrográfica do Rio Paranaíba e está situada entre as coordenadas geográficas $18^{\circ} 46^{\prime} 51^{\prime \prime}$, latitude Sul e a 46² 22' 57", longitude Oeste. Apresenta uma extensão territorial de, aproximadamente, $80,42 \mathrm{~km}^{2}$. 


\section{XIV}

Figura 1 - Localização da Sub-Bacia Hidrográfica do Córrego do Sapé.

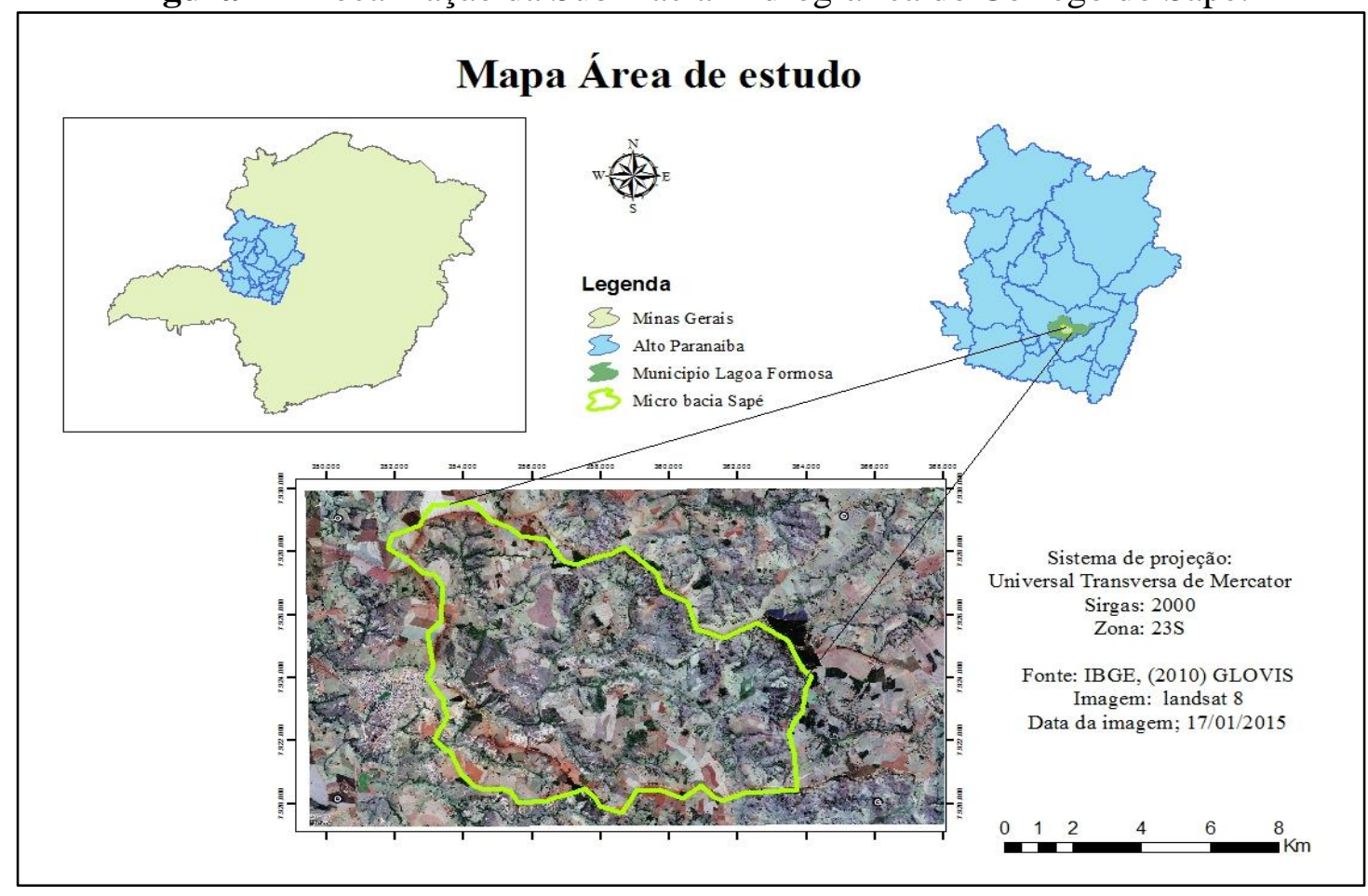

\subsection{Mapeamento do Uso e Ocupação do Solo}

Para a realização do estudo, realizou-se, previamente, a delimitação da sub-bacia e, posteriormente, uma visita de campo na área delimitada, com o intuito de se verificar "in situ" sua situação, confrontando os dados interpretados na imagem processada com a ocupação real, de modo a comprovar as classificações.

O mapeamento foi dividido em três etapas, sendo a primeira a delimitação da subbacia, a segunda o tratamento das imagens e a terceira a geração do mapa de uso e ocupação do solo, sendo utilizado em todas as etapas o software de SIG ArcGis, versão 10.2, e suas extensões, sendo esta uma versão de teste disponibilizada pelo site da ESRI (Environmental Systems Research Institute), sendo esta uma empresa norte americana que atua desde 1969 na área de SIG.

\subsubsection{Delimitação da Sub-Bacia}

Para a realização da delimitação da área de estudo, foram utilizados dados do Modelo Digital de Elevação (MDE) oriundos do SRTM (Shuttle Radar Topography Mission), obtidos no formato GeoTIFF, articulados a partir da folha topográfica do Instituto Brasileiro de Geografia e Estatística (IBGE) SE-23Y-B, em escala 1:250.000 e com resolução espacial de 90 metros, disponibilizada pela Embrapa Monitoramento por Satélite, no programa Brasil em Relevo. Entretanto, o MDE advindo do SRTM é disponibilizado sem correção, sendo necessários ajustes na rede hidrográfica, já que a hidrografia do SRTM não coincide em alguns trechos.

Os procedimentos metodológicos para a delimitação da sub-bacia do Córrego do Sapé foram subdivididos em seis etapas, sendo: preenchimento de depressões ("Fill”), direção de fluxo ("Flow Direction"), fluxo acumulado ("Flow Accumulation”), extração de drenagens 

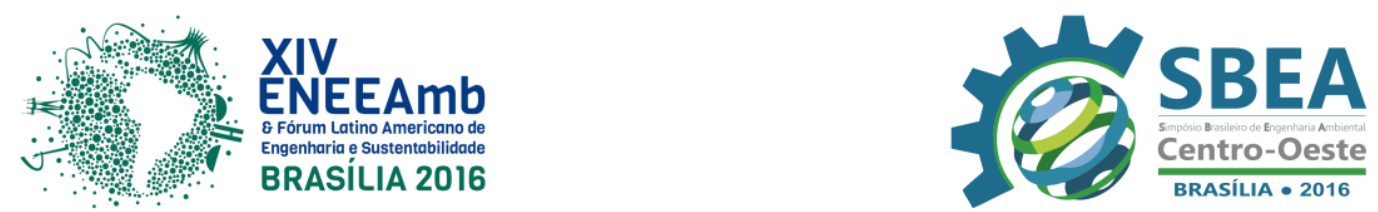

("Con"), gerar shape de drenagem ("Stream to Feature") e delimitação de bacias ("Watershed").

A primeira etapa consistiu em realizar o preenchimento das depressões e foi efetuada através do comando "Fill" no ArcGis 10.2. A etapa seguinte correspondeu à geração de um raster com a direção do fluxo através do comando "Flow Direction".

Posteriormente, gerou-se o raster do fluxo acumulado por meio do comando "Flow Accumulation". Após a realização deste procedimento, gerou-se um arquivo raster com as drenagens extraídas, por meio do comando "Con". Neste estudo, utilizou-se o valor de fluxo acumulado maior que 300 .

A quinta etapa consistiu em gerar o shape de drenagem por meio do comando "Stream to Feature" utilizando o arquivo anteriormente gerado e o arquivo de direção de fluxo gerado por meio da segunda etapa.

A última etapa consistiu em delimitar a sub-bacia com o comando "Watershed", utilizando o arquivo de direção de fluxo e o arquivo shape de ponto. $\mathrm{O}$ arquivo gerado, que possuía formato raster, foi transformado para formato shape, como polígono, para que a extração de informações, como área e perímetro, fossem possíveis.

\subsubsection{Tratamento das imagens}

As primeiras etapas processadas nas imagens utilizadas para se mapear o uso e ocupação do solo da sub-bacia estudada consistem em: seleção, aquisição e composição colorida. Assim, para a definição das tendências evolutivas das classes de uso e ocupação do solo foram utilizadas imagens de satélite, extraídas do satélite Landsat-8, referentes ao ano de 2015. Estas imagens são provenientes do sensor Operacional Terra Imager (OLI), órbita/ponto 220/73, concedidas gratuitamente, via internet, pelo USGS (United States Geological Survey).

A etapa de aquisição das imagens ocorreu por meio de inspeção visual e seleção das melhores cenas consideradas, para cada uma da órbita $\mathrm{x}$ ponto ${ }^{-1}$ que recobrem a área de estudo. $\mathrm{O}$ critério estabelecido para a seleção baseou-se na inspeção de erros presentes nas imagens e na incidência de cobertura de nuvem em áreas de interesse, bem como na observação da data das imagens.

Após a aquisição das imagens procedeu-se os processos de composição colorida, que foi realizado por meio do modelo de cores primárias aditivas, sendo elas: Red, Green e Blue (RGB) com a seguinte sequência: banda 4 (Red) no canal R, banda 3 (Green) no canal G e banda (Blue) no canal B, sendo este procedimento denominado de composição de bandas.

Após a composição colorida, as imagens passaram pelo processo de fusão de imagens com o intuito de se alcançar uma resolução espacial de 15 metros do satélite utilizado. Desta maneira, foi utilizada a imagem Multiespectral para colorir a Pancromática, sendo este processo denominado de Pan-Sharpening. Para realizar tal processo, utilizou a ferramenta "Create Pan-Sharpened Raster Dataset" do software ArcGis.

\subsubsection{Geração do mapa de uso e ocupação do solo}

Para iniciar tal etapa, foi realizado o procedimento de recorte das imagens cujo passo foi desenvolvido baseado no arquivo vetorial no formato shapefile da sub-bacia delimitada por meio da ferramenta "Buffer Wizard", disponível no software ArcGis (10.2). 

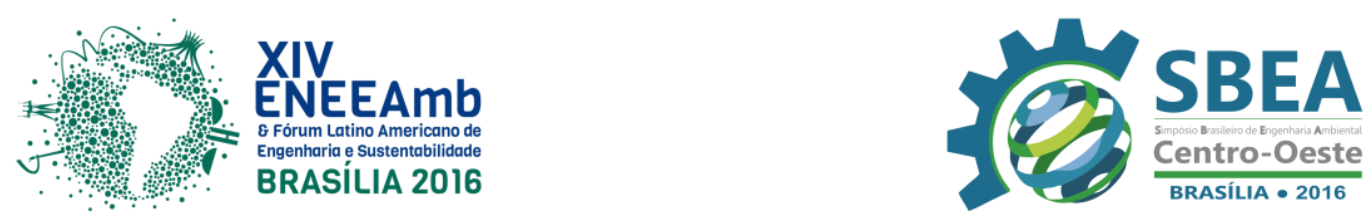

Com as imagens recortadas, os próximos passos a serem seguidos consistiram na definição de amostras, classificação, edição matricial e verificação da exatidão do mapeamento.

Para a definição das amostras, foram definidas cinco classes de uso e ocupação do solo, sendo elas: Mata Nativa, Pastagem, Cultura Anual, Solo Exposto e Infraestrutura Urbana. Para este estudo, a classe Mata Nativa correspondem às áreas que englobam qualquer tipo de vegetação que ainda não sofreu alteração humana (antrópica); a classe Pastagem se refere à cobertura vegetal abrangendo o denominado "pasto sujo"; a classe Cultura Anual caracteriza-se por lavouras que concluem seu ciclo produtivo em um ano ou em até menos tempo; a classe Solo Exposto corresponde às áreas desprovidas de vegetação ou de cultura; e a classe Infraestrutura Urbana compreende locais ocupados por áreas impermeáveis que promovem a impermeabilização do solo. Neste passo, levaram-se em consideração as características de resposta e comportamento espectral dos alvos utilizando particularidades como rugosidade, cor, textura, tamanho, forma e localização.

Após a definição das amostras, foi definido o método de classificação e o tipo de classificador. Para este estudo, adotou-se classificação supervisionada caracterizada por um conhecimento prévio do analista sobre a área de estudo (fotointerpretação, análise de fotos e mapas etc.). O processo de classificação se deu, primeiramente, por meio da criação de um vetor de polígono com o auxílio da ferramenta "Create New Shapefile". Foi inserido um novo ID na tabela de atributos a cada identificação de classe. A fim de se aumentar a separabilidade entre as classes, foram utilizados 230 polígonos.

Posteriormente, para transformar tal vetor em estatística, utilizou-se a ferramenta "Create Signatures" e a ferramenta "Maximum Likelihood" para classificar a imagem. Através destes processos, foram extraídas e definidas as áreas estaticamente homogêneas, definindo e diferenciando as classes de monitoramento estudadas.

Desta maneira, obteve-se o mapa temático, sendo assim possível a realização de uma análise quantitativa da evolução da agropecuária e supressão do Cerrado na sub-bacia e também calcular as áreas de cada classe. Para o manuseio dessa imagem no software ArcGIS 10.2 houve a necessidade de exportá-la para o formato shapefile. Desta forma, converteu-se a imagem classificada e editada do formato raster para vetor e, posteriormente, exportou tal imagem do formato vetor, para o formato shapefile.

Os dados quantitativos foram manipulados e gerenciados pelo sistema operacional Microsoft Windows, no programa de planilha eletrônica Excel, versão 2010, no qual foi possível gerar uma planilha e obter tendências para os dados da imagem classificada.

\section{RESULTADOS E DISCUSSÃO}

A partir da realização dos procedimentos metodológicos descritos anteriormente, obteve-se o mapa de uso e ocupação do solo da Sub-bacia do Córrego do Sapé (figura 2). 

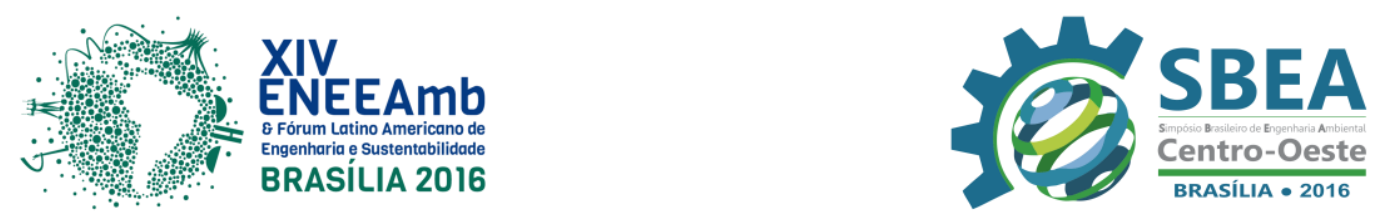

Figura 2 - Mapa de uso e ocupação do solo da Sub-bacia do Córrego do Sapé no ano de 2015.

\section{Mapa de uso e ocupação do solo \\ Microbacia do Córrego Sapé}
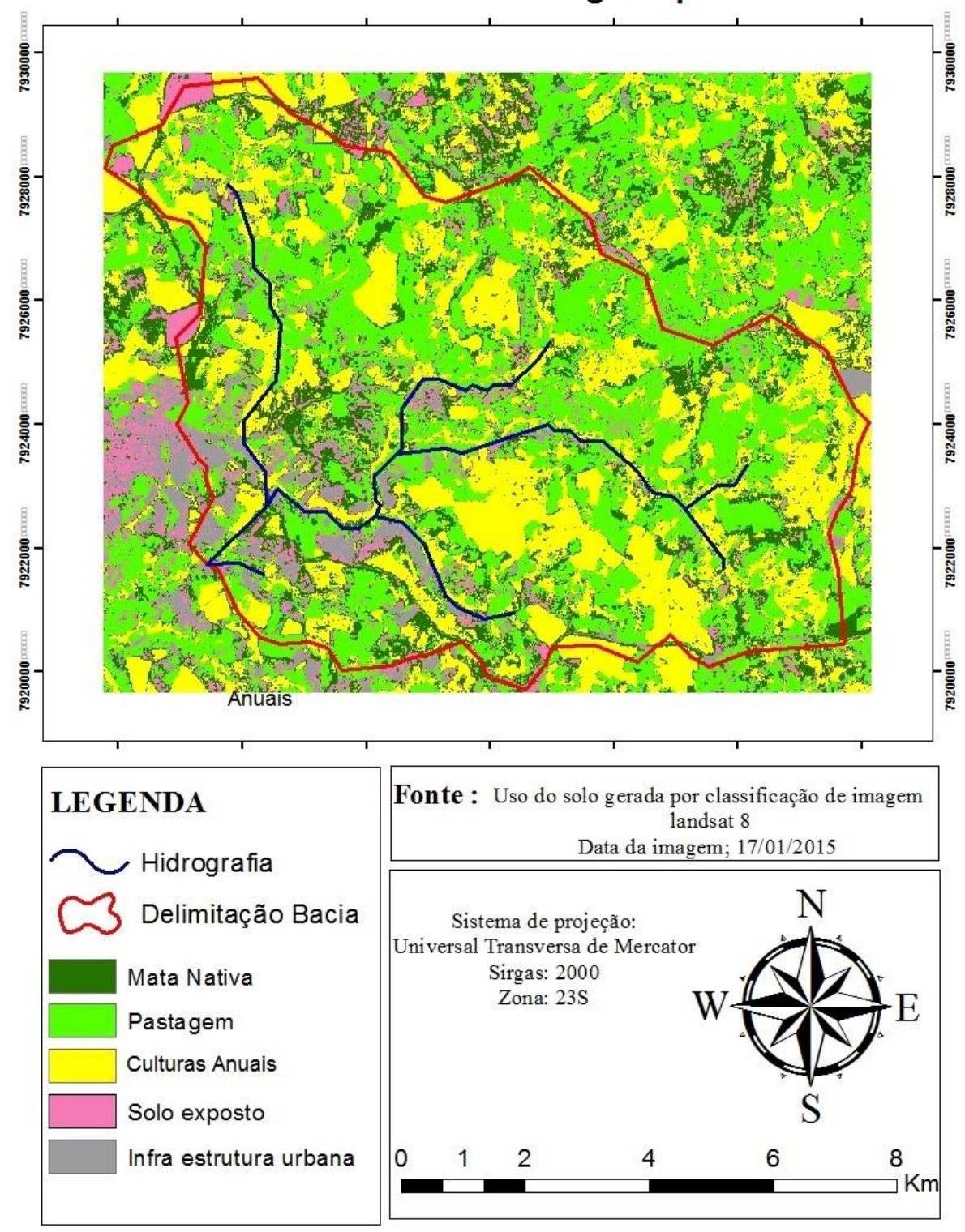

A tabela 1 apresenta as áreas e a porcentagem ocupadas pelas cinco classes na sub-bacia estudada.

Tabela 1 - Áreas e percentuais das classes do uso e ocupação do solo da Sub-bacia do Córrego do Sapé no ano de 2015

\begin{tabular}{ccc}
\hline Uso / Ocupação do Solo & Área $\left(\mathbf{k m}^{\mathbf{2}}\right)$ & Porcentagem $\mathbf{( \% )}$ \\
\hline Mata Nativa & 13,12 & 16,31 \\
Pastagem & 33,28 & 41,38 \\
Cultura Anual & 26,04 & 32,37 \\
Solo Exposto & 4,64 & 5,77 \\
Infraestrutura Urbana & 3,36 & 4,17 \\
\hline TOTAL & 80,42 & 100,00 \\
\hline
\end{tabular}



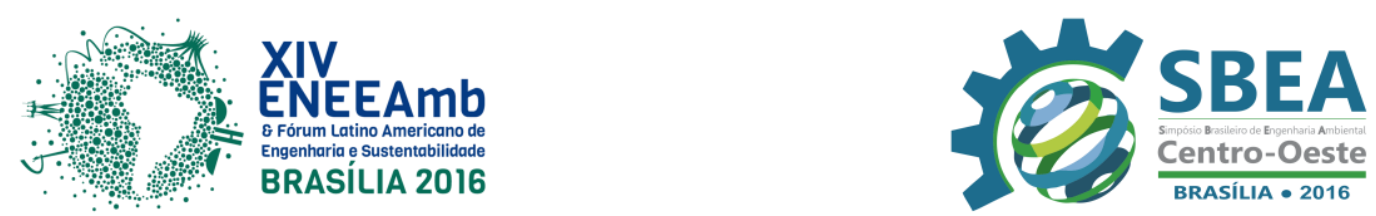

Os resultados obtidos apontam que o uso do solo predominante nesta sub-bacia é dado pela classe Pastagem, ocupando 41,38\% (33,28 $\left.\mathrm{km}^{2}\right)$ da área total, fato que pode ser explicado devido a área estudada possuir, em grande parte, características rurais, sendo observado "in situ" a criação de animais, sobretudo a criação extensiva de gado. Zigomar \& Alves (2003) concluíram em seu estudo que esta classe apresenta menores valores de infiltração de água no solo em relação à vegetação natural. Através da realização da visita de campo, também foi observado que tais estabelecimentos agropecuários se encontram sem a presença de sistemas de tratamento dos dejetos produzidos por tais animais, lançando, consequentemente, o excesso da matéria orgânica diretamente no solo e/ou na água, gerando impactos ambientais.

A classe Cultura Anual apresenta 32,37\% (26,04 $\left.\mathrm{km}^{2}\right)$ do total da área mapeada. Analisando o mapeamento, observa-se que tais culturas são distribuídas sobre as porções mais planas do relevo, fato que facilita o preparo do solo e a conservação do mesmo, bem como outras atividades pré e pós-plantio que utilizam máquinas e implementos agrícolas. A classe Cultura Anual também apresenta ameaças à saúde do meio como o grande risco existente no que se refere à contaminação do solo e da água por agrotóxicos.

A porcentagem ocupada pela classe Mata Nativa corresponde a 16,31\% (13,12 $\mathrm{km}^{2}$ ) do total, sendo a presença desta classe de suma importância no ambiente rural, uma vez que a presença de vegetação torna possível apontar uma série de benefícios ambientais decorrentes da manutenção das áreas de preservação permanente (APP). Jucá (2007) explica que tais áreas oferecem, quando manejadas de forma sustentável, vantagens ambientais, como a produção de água, e conservação do solo e conservação da biodiversidade. Na área estudada, foi observada a presença de ações de recuperação da vegetação em determinados locais que objetivam o alcance de tais benefícios citados e adequações quanto à legislação ambiental.

Com relação à classe Solo Exposto, a mesma apresenta 5,77\% $\left(4,64 \mathrm{~km}^{2}\right)$ na subbacia e são mais propensas à erosão hídrica.

A classe Infraestrutura Urbana apresenta um percentual de ocupação um pouco mais baixo que a classe Solo Exposto, com cerca de 4,17\% (3,36 km²). Tal área urbana, que compreende também as moradias rurais, representa um risco devido à impermeabilização do solo, contribuindo para a redução da vazão especifica e da qualidade da água, sendo este também o resultado observado por Vanzela, Hernandez \& Franco. (2010), ao estudarem a influência do uso e ocupação do solo nos recursos hídricos do Córrego Três Barras.

\section{CONCLUSÕES}

A utilização do sensoriamento remoto e de técnicas de geoprocessamento foi de fundamental importância para se determinar a dinâmica do uso e ocupação do solo visando à verificação do avanço das áreas antrópicas e a supressão das áreas de cerrado da sub-bacia hidrográfica do Córrego do Sapé, pois se configuram em importantes ferramentas para a detecção e mapeamento da superfície terrestre.

As metodologias utilizadas neste estudo se mostraram eficientes, já que os mapas gerados são de fácil compreensão e análise. Deste modo, conclui-se que o mapeamento do uso e ocupação do solo contribui para o conhecimento sobre as transformações das características da paisagem presentes na área de estudo.

Por meio dos resultados apresentados, é possível observar que grande parte da sub-bacia encontra-se sob uso antrópico, já que a classe que possui maior porcentagem de uso e ocupação se refere à pastagem, em que tais atividades afetam diretamente as condições 

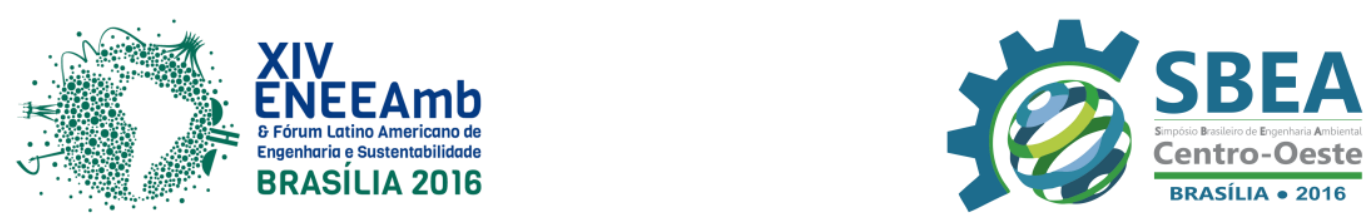

edáficas e hídricas locais. Através do exposto, podem-se apontar possíveis impactos como: perda de qualidade da água, redução na vazão hídrica, compactação do solo, erosão, assoreamento dos cursos de água, dentre outros.

A compreensão da dinâmica de ocupação do solo e de sua interferência nos processos naturais é fundamental para o estabelecimento de ações de planejamento socioambiental para a sub-bacia hidrográfica. Portanto, a partir da análise das informações e resultados gerados, poderá ser iniciado o processo de tomada de decisões e planejamentos ambiental para que possa ser melhorado as demais condições identificadas neste estudo.

\section{REFERÊNCIAS BIBLIOGRÁFICAS}

EMBRAPA. Empresa Brasileira de Pesquisa Agropecuária. Brasil em relevo. 2015. Disponível em: < http://www.relevobr.cnpm.embrapa.br/>. Acesso em: 15 abr. 2015.

IBGE. Instituto Brasileiro de Geografia e Estatística. Downloads. 2010. Disponível em: <http://www.ibge.gov.br>. Acesso em: 06 mai. 2015.

JUCÁ, F. T. Marcos legais sobre reserva legal e áreas de preservação permanente: uma estratégia para conservação dos recursos naturais. 2007. 45 f. Monografia (Título de Engenheiro Florestal - Instituto de florestas, Universidade Federal Rural do Rio de Janeiro, Rio de Janeiro, 2007.

ROSA, R. Introdução ao sensoriamento remoto. 5. ed. Uberlândia: EDUFU, 2003. 135 p.

SANTOS, A. L. C.; SANTOS, F. Mapeamento das classes de uso e cobertura do solo da bacia hidrográfica do rio Vaza-Barris, Sergipe. SABER ACADÊMICO - UNIESP. 10 ed. Presidente Prudente, $\quad$ dez. $2010 . \quad$ Disponível em:< http://www.uniesp.edu.br/revista/revista10/pdf/artigos/06.pdf $>$. Acesso em: 10 abr. 2015.

SILVA, K. L.; et al. Mapeamento e análise do uso e ocupação do solo da bacia do rio cuiá a partir de imagem do satélite quickbird. In: Congresso Norte-Nordeste de Pesquisa e Inovação, 5, 2010, Maceió. Anais eletrônicos... Maceió: CONNEPI, 2010. Disponível em: <http://connepi.ifal.edu.br/ocs/index.php/connepi/CONNEPI2010/paper/viewFile/1655/941>. Acesso em: 10 abr. 2015.

USGS - United States Geological Survey. Download GLOVIS. 2015. Disponível em:< http://glovis.usgs.gov/distribution/download_notices.shtml>. Acesso em: 15 abr. 2015.

VAEZA, R.F. Uso e Ocupação do Solo em Bacia Hidrográfica Urbana a Partir de Imagens Orbitais de Alta Resolução. Floresta e Ambiente - Revista da Universidade Federal Rural do Rio de Janeiro (UFRRJ), Rio de Janeiro, v.17, jan. - jun. 2010.

VANZELA, L. S.; HERNANDEZ, F. B. T.; FRANCO, R. A. M. Influência do uso e ocupação do solo nos recursos hídricos do Córrego Três Barras, Marinópolis. Revista Brasileira de Engenharia Agrícola e Ambiental. Campina Grande v.14. n.1. 2010.

ZIGOMAR, M. S.; ALVES, M. C. Movimento de água e resistência à penetração em um Latossolo Vermelho distrófico de cerrado, sob diferentes usos e manejos. Revista Brasileira de Engenharia Agrícola e Ambiental, Campina Grande, v. 7, 2003. 